\title{
MITRAL VALVE REPAIR FOR MITRAL REGURGITATION IN THE ELDERLY: YES, WE HAVE TO, BUT LOOK AT THE ETIOLOGIES!
}

Antonio Calafiore ${ }^{1}$, Massimo Di Marco ${ }^{2}$, Stefano Guarracini ${ }^{3}$, Kostas katsavrias ${ }^{4}$, and Michele Di Mauro 5

${ }^{1}$ John Paul II Foundation for Research and Treatment

${ }^{2}$ Ospedale Civile dello Spirito Santo

${ }^{3}$ Private Hospital Pierangeli Srl

${ }^{4}$ Henry Dunant Hospital Center

${ }^{5}$ Maastricht UMC+

March 9, 2021

\begin{abstract}
The meta-analysis by Di Tommaso et al demonstrated as elderly patients with mitral regurgitation (MR) undergoing mitral valve repair ( $\mathrm{MVr}$ ) had lower short-term mortality and higher long-term survival with respect to patients undergoing mitral valve replacement (MVR). The benefit of repair is such, that initial surgical strategy is advisable in the elderly even in case of mild symptoms if compared with conservative management. However, even if repair can be performed in presence of some specific etiologies, as degenerative MR or secondary MR, there are always cases where a replacement can be an acceptable solution compared to a repair with uncertain future, regardless of our believes and our technical ability. In this subset of patients, the literature does not show any improvement in outcome of transcatheter mitral repair. Mitral valve repair has to be always done, but look at the etiologies and to the consequences that what is done today can cause tomorrow.
\end{abstract}

MITRAL VALVE REPAIR FOR MITRAL REGUGITATION IN THE ELDERLY: YES, WE HAVE TO, BUT LOOK AT THE ETIOLOGIES!

Antonio M Calafiore, MD (1), Massimo Di Marco (2), MD, Stefano Guarracini (3), MD, PhD, Kostas Katsavrias (4), MD, Michele Di Mauro (5), MD, PhD, MSc.

1. Department of Cardiovascular Sciences, Gemelli Molise, Campobasso, Italy

2. Department of Cardiology, "Santo Spirito" Hospital, Pescara, Italy

3. Department of Cardiology, "Pierangeli" Hospital, Pescara, Italy

4. Department of Cardiac Surgery, Henry Durant Hospital, Athens, Greece

5. Cardio-Thoracic Surgery Unit, Heart and Vascular Centre, Maastricht University Medical Centre (MUMC), Cardiovascular Research Institute Maastricht (CARIM).

\section{Corresponding author}

Antonio M. Calafiore, MD

Department of Cardiovascular Diseases

Gemelli Molise

Largo A. Gemelli 1, 86100 
Campobasso, Italy

email:am.calafiore@gmail.com

Abstract

The meta-analysis by Di Tommaso et al demonstrated as elderly patients with mitral regurgitation (MR) undergoing mitral valve repair $(\mathrm{MVr})$ had lower short-term mortality and higher long-term survival with respect to patients undergoing mitral valve replacement (MVR). The benefit of repair is such, that initial surgical strategy is advisable in the elderly even in case of mild symptoms if compared with conservative management. However, even if repair can be performed in presence of some specific etiologies, as degenerative MR or secondary MR, there are always cases where a replacement can be an acceptable solution compared to a repair with uncertain future, regardless of our believes and our technical ability.

In this subset of patients, the literature does not show any improvement in outcome of transcatheter mitral repair.

Mitral valve repair has to be always done, but look at the etiologies and to the consequences that what is done today can cause tomorrow.

In this issue Di Tommaso et $\mathrm{al}^{1}$ report a meta-analysis of studies comparing mitral valve repair (MVr) and mitral valve replacement (MVR) for mitral regurgitation (MR) in the elderly. Results support once again our previous knowledge. Patients undergoing MVr had lower short-term mortality and higher long-term survival. Moreover, the incidence of postoperative stroke was $2.1 \%$ in MVr versus $4.8 \%$ in MVR patients, with a p-value close to statistical significance (0.07).

The benefit of MV repair in the elderly, if compared with replacement ${ }^{2}$ has been known since long time, with survival similar to that of the general population in patients undergoing repair ${ }^{3}$. These findings were confirmed by recent publications ${ }^{4}$. An analysis of the STS database performed by Hendrix et $\mathrm{al}^{5}$ in patients with degenerative MR demonstrated lower early mortality in repair compared to all the techniques of replacement (no, partial or complete chordal preservation).

The benefit of repair is such, that initial surgical strategy is advisable in the elderly even in case of mild symptoms if compared with conservative management ${ }^{6}$.

These recent results are in contrast with the data previously reported in a meta-analysis by Andalib et $\mathrm{al}^{7}$ in 2014, who showed, in studies with more than 50 patients [?]80 years who underwent MV surgery, an early mortality associated with MVr and MVR of $6 \%$ and $16 \%$, respectively. One-year and 5-year survival was $69 \%$ and $23 \%$ in case of MVr, similar to that of MVR patients (67\% and $29 \%$, respectively). It is noteworthy that purpose of that paper was to evaluate the possible role of transcatheter MV repair or replacement in the elderly. The Authors suggested that, as surgery was associated with high early and late mortality, transcatheter therapies could be a valid alternative in selected patients.

However, transcatheter mitral repair in the elderly did not show improvement in outcome. Buzzatti et al ${ }^{8}$ showed that, in patients aged 75 years or more and STS PROM [?]8, after weighting, the use of MitraClip had a rate of postoperative complications lower than surgical repair, but increased mitral regurgitation. One-year survival was higher in MitraClip compared to surgical population $(97.6 \%$ vs $95.3 \%, \mathrm{p}=0.09)$, but 5 -year survival was lower $(34.5 \%$ vs $82.2 \%, \mathrm{p}<0.001)$. Five-year MR [?]3 was as well more frequent in MitraClip patients $(36.9 \%$ vs $3.9 \%, \mathrm{p}<0.001)$. Alozie $\mathrm{et}^{9}{ }^{9}$, in patients aged [?] 80 years, showed that the use of MitraClip was associated to higher 1-year mortality compared to patients who underwent surgical MVr (21.4\% vs $9.5 \%$ ). Residual MR [?]2 at discharge was present in none of the surgical patients and in $23.8 \%$ of the patients treated with MitraClip. Superiority of surgical repair over transcatheter repair, at least in low or intermediate risk elderly patients, seems to be well demonstrated.

However, even if surgery still remain the golden standard for the treatment of MR and repair seems to be the most effective technique to be applied when possible in most elderly patients, we have not to abandon our common sense. Even if repair can be performed in presence of some specific etiologies, as degenerative MR 
or secondary MR, there are always cases where a replacement can be an acceptable solution compared to a repair with uncertain future, regardless of our believes and our technical ability. This meta-analysis ${ }^{1}$ shows that patients with rheumatic MR have, correctly, a high prevalence of MVR (87\%) and nobody doubts that MVR is the best solution for this etiology, irrespective of the global concept of the superiority of repair on replacement. On the other side, we know that degenerative MR can be, in expert hands, repaired in many patients $\left(65 \%\right.$ in this study $\left.{ }^{1}\right)$ with good long-term freedom from residual MR. But in patients with ischemic MR repair failure can be high in the mid-term ${ }^{10}$ and the risk of a reoperation can be often less acceptable than in younger patients.

Most of the studies deal only with early and late survival, but nothing is said about functional outcome and problems related to MR return. This aspect of the decision depends on us, and the best technical procedure (repair) has to be weighted against higher prevalence of failure of repair, in particular when repair is complex and a longer pump run can affect the outcome of a patient with some comorbidities.

Repair has to be always done, but look at the etiologies and to the consequences that what is done today can cause tomorrow.

\section{REFERENCES}

1. Di Tommaso E, Rapetto F, Guida GA, Zakkar M, Bruono VD. Benefits of mitral valve repair over replacement in the elderly: a systematic review and meta-analysis. J Card Surg, 2021, in press.

2. Enriquez-Sarano M, Schaff HV, Orszulak TA, Tajik AJ, Bailey KR, Frye RL. Valve repair improves the outcome of surgery for mitral regurgitation. A multivariate analysis. Circulation 1995;91:1022-8.

3. Ghoreishi M, Dawood MY, Gammie JS. Mitral valve surgery in elderly patients with mitral regurgitation: repair or replacement with tissue valve? Curr Opin Cardiol 2013;28:164-9.

4. Gotte J, Zittermann A, Hakim-Meibodi K, et al. Long-Term Clinical Outcome in Elderly Patients Undergoing Mitral Valve Repair. Thorac Cardiovasc Surg 2020.

5. Hendrix RJ, Bello RA, Flahive JM, et al. Mitral Valve Repair Versus Replacement in Elderly With Degenerative Disease: Analysis of the STS Adult Cardiac Surgery Database. Ann Thorac Surg 2019;107:74753.

6. Kang $\mathrm{DH}$, Heo $\mathrm{R}$, Lee $\mathrm{S}$, et al. Initial surgery versus conservative management of symptomatic severe mitral regurgitation in the elderly. Heart 2018;104:849-54.

7. Andalib A, Mamane S, Schiller I, et al. A systematic review and meta-analysis of surgical outcomes following mitral valve surgery in octogenarians: implications for transcatheter mitral valve interventions. EuroIntervention 2014;9:1225-34.

8. Buzzatti N, Van Hemelrijck M, Denti P, et al. Transcatheter or surgical repair for degenerative mitral regurgitation in elderly patients: A propensity-weighted analysis. J Thorac Cardiovasc Surg 2019;158:86-94 e1.

9. Alozie A, Paranskaya L, Westphal B, et al. Clinical outcomes of conventional surgery versus Mitra$\operatorname{Clip}(\mathrm{R})$ therapy for moderate to severe symptomatic mitral valve regurgitation in the elderly population: an institutional experience. BMC Cardiovasc Disord 2017;17:85.

10. Calafiore AM, Totaro A, Sacra C, Foschi M, Gaudino M, Di Mauro M. Failure of annuloplasty alone to correct ischemic mitral regurgitation. What we learned from two randomized controlled trials. J Card Surg 2019;34:155-7. 